\title{
Emotional Design in Multimedia Learning: How Emotional Intelligence Moderates Learning Outcomes
}

\author{
Jeya Amantha Kumar \\ Centre for Instructional Technology and Multimedia, Universiti Sains Malaysia \\ Email: jeya.amantha@gmail.com \\ Balakrishnan Muniandy \\ Centre for Instructional Technology and Multimedia, Universiti Sains Malaysia \\ Email: mbala@usm.my \\ Wan Ahmad Jaafar Wan Yahaya \\ Centre for Instructional Technology and Multimedia, Universiti Sains Malaysia \\ Email:wajwy@usm.my
}

\begin{abstract}
This study is designed as a preliminary study to explore the effects of emotional intelligence (EI) on achievement, perceived intrinsic motivation and perceived satisfaction when expose to an emotional designed Multimedia Learning Environment (MLE) that was designed to induce either positive, neutral or negative emotions. All three designs had similar content and narration but differed in visual element such as colour, font size, font style and images. Based on the findings, it was reported that students performed better in the design used to induce negative emotion (NegD design) followed by the positive (PosD) and Neutral (NeuD). There is no significant difference in levels of emotional intelligence towards these learning outcomes; however, students with Low EI performed better overall. EI only qualified perceived satisfaction when using a MLE designed to induce emotions and it was found that students with Low EI preferred the design that induces positive emotions. In addition, High EI students favored designs with emotionality (positive or negative) compared to neutral design.
\end{abstract}

Index Terms-Emotional Design, Engineering Education, Emotional Intelligence, Multimedia- Based Learning, Aesthetics.

\section{INTRODUCTION}

A question was raised on the possibilities of multimedia learning environments (MLE) fostering positive emotions and in the same time improving learning outcomes [1]. It was reported that designing a MLE to induce positive emotion increased comprehension, transfer of knowledge and reduced the perception of learning difficulty [1]. Their study compared two emotional design; positive and neutral. The positive designed MLE was developed to induce positive emotions such as joy and happiness whereas the neutral MLE was designed to neither induce positive nor negative emotions. Therefore, could a negative designed MLE that induces negative emotions such as by using colours and images (negative aesthetics) have a positive impact on learning? It has been reported that negative emotions has a positive quality about it that could improve learning [2]. However, in this context we discuss the effects of negative aesthetics and there is a need to investigate the impact of visual aesthetics that induces negative affect [3], [4]. Thus, this study will explore and compare the effects of induced positive, neutral and negative emotion on learning outcome and in the same time introduce the effects of emotional intelligence (EI) when emotions are induced in a MLE. Based on the Cognitive and Affective Theory of Learning with Media (CATLM) there is a need to include meta-cognitive factors in identify its effects on multimedia-based learning [5].

Therefore, why EI? EI influences e-learning [6], [7] however, there is insufficient research on the effect of EI as an influencing factor in e-learning and should be investigated [8], [9]. Individuals with high EI are those who are highly capable of managing emotion Hence, when expose to induced emotions, does this rule still apply? Could a person's EI influence how he or she perceives different design?

\section{LITERITURE REVIEW}

\section{A. Emotion and learning}

To understand how emotions influence e-learning, the discussion e starts with an exploration in regards to emotions in learning. A student could experience a variety of emotions ranging from positive to negative emotions while learning [10]. Positive emotions are emotional states such as enjoyment, pride and satisfaction whereas negative emotions are emotional states such as 
anger, anxiety and frustration [11]. Emotions play a significant role as a state that could begin, end or obstruct learning hence concluding that both positive and negative emotions have its pros and cons [2]. As an example, positive emotions could create curiosity, creativity and improve learning however it could reduce focus of the mind [12]. On the other hand, negative emotion such as anxiousness could actually aid in focusing the mind [13]. However seen, emotions play a vital role in learning [2] and any learning system that neglects emotions would yield ineffective learning outcomes [14].

\section{B. Emotions and multimedia learning}

Multimedia learning is learning that takes place by using words and pictures [15]. When we design with multimedia we are designing based on how people learn [16] and every single multimedia element induces emotion [17]. Emotion is the factor that "connects a multimedia design to multimedia learning and also the designer to the user" [3, p.125].

Integrating emotions in multimedia could be implemented based on two approaches; by visual design or instruction. The design aspect deals with the interface design of the multimedia and the instruction aspect is based on using instructional design method such as Fear, Envy, Anger, Sympathy and Pleasure (FEASP) model and the Emotional and Cognitive Aspects of Learning (ECOLE) model [18]. It is suggested using the design aspect as it has better emotional impact especially concerning motivation and satisfaction [19]. For MLE this approach has been implemented by [8, 21, 22].

Interface design and audio induces emotions and activates cognitive activities in MLE [21]. A model for integrating emotion in multimedia learning which is based on theories in the field of emotions, multimedia learning and multimedia design (Figure 1) was developed by [22]. It was suggested that the use of multimedia aesthetics such as by integrating colour, graphics, text, audio, and video could induce positive emotion in learning. This method was also supported by [20] and their study added that anthropomorphism and baby-face bias as additional design element that could be used to induce emotion in a MLE.
Never the less, every multimedia element used in a MLE has different impact towards a person's emotion. How these emotions are created is based on the users' perception. According to the cognitive appraisal theory of emotion, emotions are the outcome of a person's appraisal on a situation or object [22]. By appraising, humans would create a like / dislike relationship with the object or situation. The emotional valance (positive-like or negative-dislike) established here would be the determining factor on the user's perception on the media. In this way, it highlights the importance of aesthetics in multimedia as mentioned by [21]. Aesthetics are defined by our perception and judgement of our environment through our senses [23]. It is the pleasure gained through our senses [24]. Any design that is aesthetically pleasing could change a person's emotional state and change their judgement on a product [13]. The theory that defines this process is called emotional design.

\section{Emotional Design in Multimedia}

According to Donald Norman's theory of emotional design, appealing designs are designs that influence the user based on three levels; visceral, behaviour, and reflective [13]. The visceral level is based on the first impression the user has on the physical attributes of the product such as colour and smoothness [25]. Behavioural level defines perception relating to products usability and efficiency and lastly the reflective level is based on how the user relates to a product. When a learning tool is designed to fulfil the visceral, behavioural, and reflective requirements of the user, a positive affect could be found in the learning activity because it improves creativity and problem solving skills [26]. Emotional design principles may be implemented in multimedia design as emotions produced through these designs have a major influence on the learning experience [20]. Thus by understanding the interrelationship between emotion and design, designers will be empowered to influence the user's emotional state [26]. Emotions and cognition go hand in hand [13] Empirical research [21, 22, 28 and 29] relevant to emotion induction in multimedia learning has also investigated the relationship between emotion and cognition in learning.

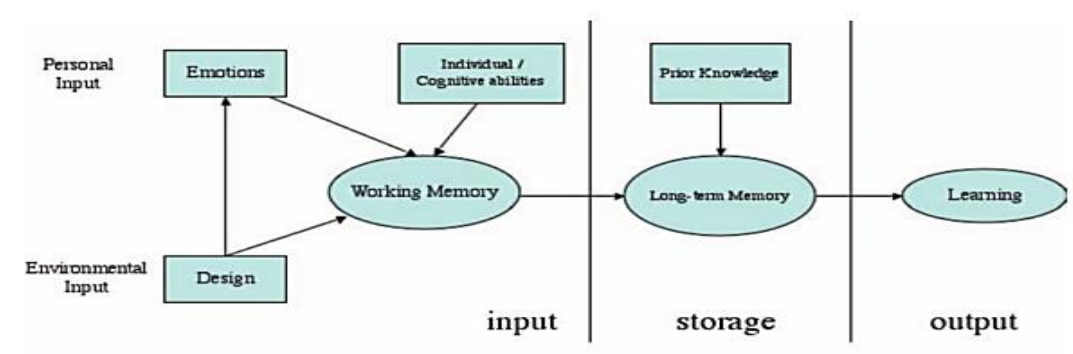

Fig.1. A model of emotional design in multimedia learning [21, p.188]

In this study, the cognitive affect will be studied based on learning achievement. According to the Commonwealth Educational Media Centre for Asia it is important to evaluate learning achievements to measure the success of the learning activity [29]. Whereas emotional affect could be investigated based on the evaluation of engagement, motivation, satisfaction [21], self-efficacy, learning styles and emotional intelligence [30]. However, motivation and satisfaction are two factors that should be considered as it relates to the 
concept of emotional design [13] and also relevant to emotion integration in an e-learning environment [19].

So how is motivation relevant to emotion and learning? Emotions are the driving force for motivation [31]. From the education perspective motivation is an important factor in human learning [32] as it defines the relationship between students' personal characteristics and their learning achievement [33]. In addition a student that is intrinsically motivated will be able to learn based on their own satisfaction and enthusiasm irrespective of any grade or reward [34]. Satisfaction has a strong effect on the intention to use an e-learning system [35]. It also has a strong tie with a students intrinsic motivation [34] and emotional intelligence [36].

\section{Emotional intelligence in multimedia learning}

Emotional intelligence (EI) is defined as "the ability to monitor one's own and others' feelings and emotions, to discriminate among them and to use this information to guide one's thinking and actions" [37, p.189]. EI helps to achieve goals by managing their negative emotions [38]. It plays an important role in a person education as it helps to develop a balance individual [39]. EI has been found to be an important factor that contributes to academic excellence even when other factors such as personality and cognitive abilities were controlled [9]. EI was also found to be a primary factor in the success of e-learning [40]. High EI students were achievement - oriented, innovative and highly motivated. However, student with low EI perceive e-learning negatively as it requires higher levels of "self-discipline, independent effort, maturity, time management skills, and positive attitude" [31,p.66]. However, the effect of EI in e-learning is still underexplored [8]. Maybe by understanding the influence of EI in managing emotions in e-learning could be by an eye opener on how it effects online learning [7].

\section{RESEARCH OBJECTIVE}

The purpose of this study is to investigate the effects of emotional intelligence (EI) on students learning achievement, perceived intrinsic motivation and perceived satisfaction when expose to a Multimedia Learning Environment (MLE) that was designed to induce either positive, neutral or negative emotions. This study reports the preliminary findings on the effects of EI and induced emotions in MLE on learning outcome.

\section{RESEARCH QUESTIONS}

This study is designed to answer the following research questions:

1. What is the effect of a Multimedia Learning Environment (MLE) designed to induce positive, neutral or negative emotions on learning achievement, perceived intrinsic motivation and perceived satisfaction while learning?
2. What is the effect of different levels of emotional intelligence (EI) on students learning achievement scores, perceived intrinsic motivation and perceived satisfaction when exposed to a Multimedia Learning Environment (MLE)?

3. What is the effect of emotional intelligence (EI) on students learning achievement scores when exposed to a Multimedia Learning Environment (MLE) designed to induce positive, neutral or negative emotions?

4. What is the effect of emotional intelligence (EI) on perceived intrinsic motivation when exposed to a Multimedia Learning Environment (MLE) designed to induce positive, neutral or negative emotions?

5. What is the effect of emotional intelligence (EI) on perceived satisfaction when exposed to a Multimedia Learning Environment (MLE) designed to induce positive, neutral or negative emotions?

6. What is the interaction effect between emotional intelligence (EI) on learning achievement scores, perceived intrinsic motivation and perceived satisfaction when expose to a Multimedia Learning Environment (MLE) that was design to induce positive, neutral or negative emotions?

Therefore the hypotheses of this study are :

H0 : There is no significant difference between students learning achievement scores, perceived intrinsic motivation and perceived satisfaction when exposed to a Multimedia Learning Environment (MLE) that was design to either induce positive, neutral or negative emotions.

$\mathbf{H O}_{2}$ : There is no significant difference between student with high levels of emotional intelligence and low levels of EI on students learning achievement scores, perceived intrinsic motivation and perceived satisfaction when exposed to a Multimedia Learning Environment (MLE).

H0 $_{3}$ : There is no significant difference between students emotional intelligence on learning achievement scores when expose to a Multimedia Learning Environment (MLE) that was design to induce positive, neutral or negative emotions.

H0 : There is no significant difference between students emotional intelligence on perceived intrinsic motivation when expose to a Multimedia Learning Environment (MLE) that was design to induce positive, neutral or negative emotions. 
H05: There is no significant difference between students emotional intelligence on perceived satisfaction when expose to a Multimedia Learning Environment (MLE) that was design to induce positive, neutral or negative emotions.

H06 : There is no significant interaction effect between students emotional intelligence on learning achievement scores when expose to a Multimedia Learning Environment (MLE) that was design to induce positive, neutral or negative emotions.

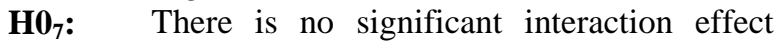
between students emotional intelligence on perceived intrinsic motivation when expose to a Multimedia Learning Environment (MLE) that was design to induce positive, neutral or negative emotions.

H08: There is no significant interaction effect between students emotional intelligence on perceived satisfaction when expose to a Multimedia Learning Environment (MLE) that was design to induce positive, neutral or negative emotions.

\section{Methodology}

This section will discuss the design and development of the MLE, instruments, participants and procedures used to develop the study.

\section{A. Design of the MLE}

The design and development of the MLE /courseware was done based on the Instructional Design model of Frey and Sutton (2010), Gagne's Nine Events of Instruction, Mayers' Cognitive Theory of Multimedia Learning [16], and empirical research on aesthetic design that induces either positive, neutral or negative emotions from the user. The designs are categorised as Positive Design (PosD), Neutral Design (NeuD) and Negative Design (NegD). All three designs had the same content and narration and were developed based on the Malaysian Polytechnic syllabus of EE503: IC Fabrication and Packaging Technology for the topic of silicon fabrication. The screenshots for the designs are provided in Figure 2.

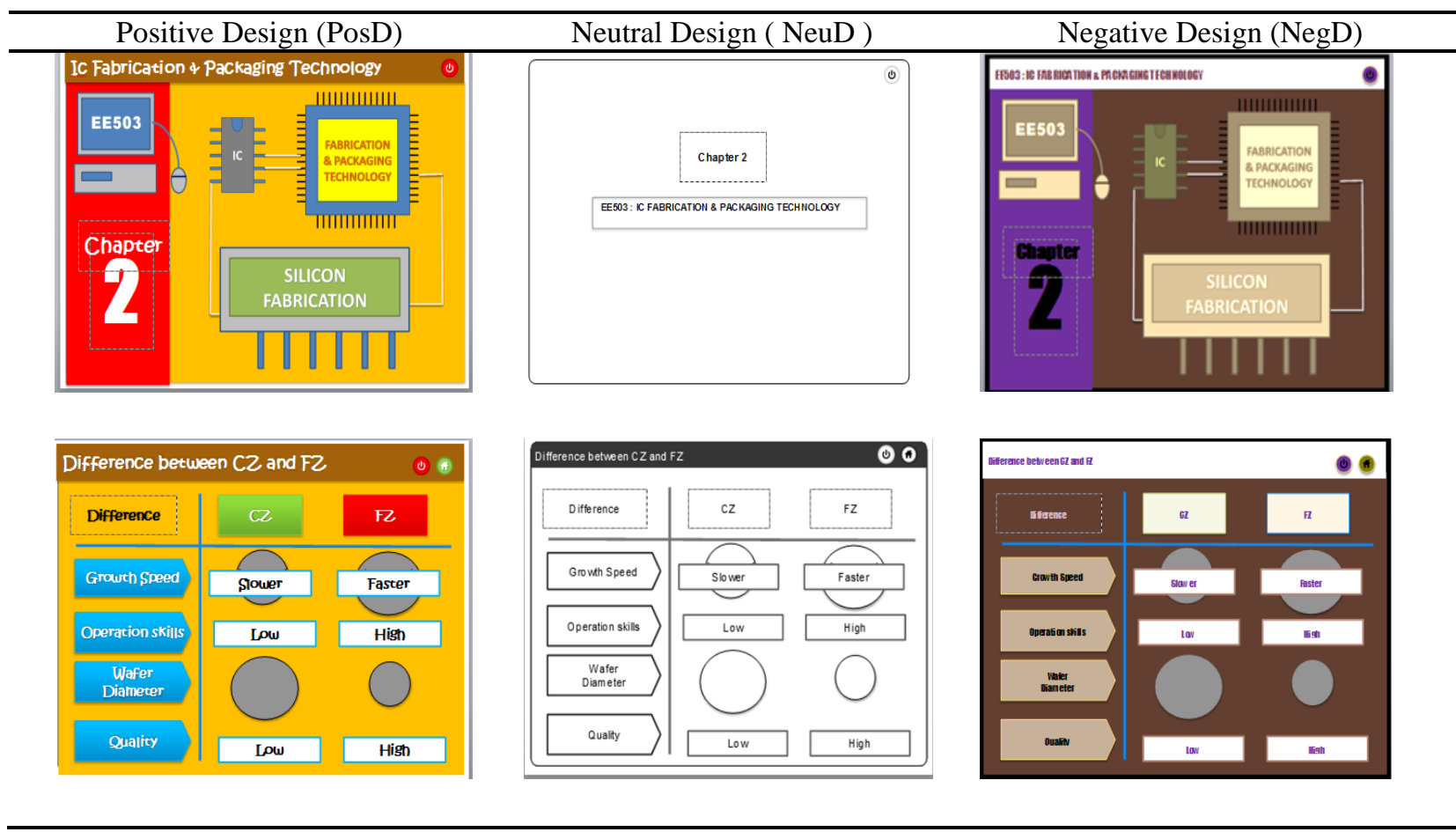

Fig.2. Screen shots of the as Positive Design (PosD), Neutral Design (NeuD) and Negative Design (NegD)

Each design is distinguish by different multimedia elements, such as colour, font and graphics. Selection of these multimedia elements are based on empirical studies established by the relationship between these elements and the emotions it induces. However, all the designs had the same narration, duration and navigational options. The first and commonly most used element in multimedia is colour. To induce positive emotion the colours used are bright colours of red, blue and green with bright warm colours of yellow, orange and brown. The selection of colour is highly dependent on cultural preference as studies have stipulated that every culture has different perspective on different colours. Neutral state was induced using shades of grey, white and black and lastly negative emotions was induced with colours such as white, brown, purple and colours that have low brightness and were dull. The colours applied are based on research done by [21], [22] and [43] 
The type of font and the size applied are based on the research by [21], [42-45]. To induce positive emotions, Kristen ITC font type sized between 15-24 point were used. The neutral font applied was Arial size 14point and lastly to induce negative emotion, the font applied was Impact size between $10-13$ point. As for images, images were selected based on affect valance [12], [17], [21], [46]. Affective images selected were based on literature that happy and bright images induced positive emotions whereas sad and cool images induced negative emotions

\section{B. Instruments}

In this study, three instruments were used to identify the learning outcomes and one instrument to determine student's level of emotional intelligence. These instruments are the Pretest and Posttest to measure student's achievement, Post-Experimental Intrinsic Motivation Inventory, E-Learning Satisfaction (ELS) Inventory and the Traits Emotional Intelligence Questionnaire - Short Form (TEIQue - SF).

Students learning achievement score are defined by the difference between the pretest and posttest scores [47]. Questions for the pre and posttest were developed based on the objectives provided in the syllabus of the IC Fabrication and Packaging Technology (EE503) from the Department of Polytechnic Education of Malaysia. 20 objective questions were developed and used for the pre and posttest evaluation. The test takes about 15 to 20 minutes to complete. The Post-Experimental Intrinsic Motivation Inventory (IMI) was developed by Edward L. Deci and Richard M. Ryan of University of Rochester based on the Self-Determination Theory (SDT). The version used in this study could be obtained from the website http://selfdeterminationtheory.org. The IMI measures three subscales which are value/usefulness, interest/enjoyment and perceived choice. The instruments has a reliability value of 0.71 and has been used for the Malaysian sample [48]

The E-Learning Satisfaction (ELS) Inventory was developed by Wang Yi-Shun to measured students online learning experience [49]. The instrument measures learners satisfaction based on interface design, learning community, content and personalisation. However, to suit the need of this study only the items concerning interface design and content were applied. The instrument has a reliability of .95 [49] and .92 [50] when used on 86 undergraduate students of Universiti Teknologi MARA (UiTM). Traits Emotional Intelligence Questionnaire Short Form (TEIQue-SF) was developed by Petrides and Furnham [51] to measure global trait emotional intelligence. It has 30 items and it is a free version that could be used for educational purposes. The version could be downloaded from http://www.psychometriclab.com. TEIQue - SF is also a reliable method in assessing student's intrinsic motivation for Malaysian sample [52], [53]. All instruments used in this study excluding the pre and posttest are measured based on a 7-point Likert scale ranging from 1 (strongly disagree) to 7 (strongly agree). The categorisation is based on the mean score, where students that score below the calculated mean will be classified as "Low" and those scoring higher than the mean score will be classified as "High".

\section{Participants}

For this study 33 Diploma of Electronic Engineering students from a northern polytechnic in Malaysia were selected. They were enrolled in the EE503: IC Fabrication and Packaging Technology course. Students were randomly assigned to three different groups of Positive Design (PosD), Neutral Design (NeuD) and Negative Design (NegD).

\section{Procedures}

The initial testing stage requires the students to answer to the Traits Emotional Intelligence Questionnaire - Short Form (TEIQue - SF). The evaluation on the levels of EI was done one day before to ensure there would be sufficient number of students for each category of Positive Design (PosD), Neutral Design (NeuD) and Negative Design (NegD). Prior exposing the student to the MLE, students were required to answer 20 objective questions (pretest). After completing the test, students were assigned to different designs of the multimedia learning environment (positive, neutral or negative design). The time allocation to go through the MLE was 30 minutes and after completing the learning activity students were given the posttest questions. This was followed by the Post-Experimental Intrinsic Motivation Inventory and the E-Learning Satisfaction (ELS) Inventory evaluation. Students were thanked and debriefed. It must be highlighted that students were not expose to their Traits Emotional Intelligence Questionnaire - Short Form (TEIQue - SF) scores as this exposure might interfere with the learning activity and other evaluation.

\section{FINDINGS}

The 33 participants were categorised based on the Table 1. $42.4 \%$ of the students had high emotional intelligence (HEI) and $57.6 \%$ had low emotional intelligence (LEI). 11 students were assigned to each group of Positive Design (PosD), Neutral Design (NeuD) and Negative Design (NegD).

Table 1. Student Categorisation

\begin{tabular}{ccccc}
\hline EI & \multicolumn{3}{c}{ Design type } & Total \\
\cline { 2 - 4 } Category & PosD & NeuD & NegD & \\
\hline High & 5 & 5 & 5 & 15 \\
Low & 6 & 6 & 6 & 18 \\
Total & 11 & 11 & 11 & 33 \\
\hline
\end{tabular}

Note $:$ PosD = Positive Design; NeuD = Neutral Design; NegD $=$ Negative Design

Based on the data analysed, it was found that all the instruments resulted in an above average mean score; Post-Experimental Intrinsic Motivation Inventory $(M=5.409)$, E-Learning Satisfaction (ELS) Inventory $(M=5.997)$ and the Traits Emotional Intelligence 
Questionnaire - Short Form (TEIQue - SF) (M=4.730). The mean value for the learning gain score, perceived intrinsic motivation and satisfaction score for every design type is shown in Table 2. Based on the findings it is found that the students had the highest learning gain score $($ mean $=4.00)$, perceived intrinsic motivation $($ mean=5.516) and satisfaction score $($ mean=6.182) for the NegD design, followed by the PosD and NeuD design. However, based on an ANOVA test, it was found that the difference between the groups were not significant in all learning outcomes.

Based on the analysis on the difference between learning outcomes in a MLM and levels of EI, it was found that students with Low EI performed better than students with High EI (Table 3). However, based on a ttest performed, it was found that in all cases (learning achievement scores, perceived intrinsic motivation and perceived satisfaction) the difference between levels of EI to be not significant. This test is irrelevant to the type of MLE design used by the students.
A two-way ANOVA was done on design type (PosD, NeuD, and NegD) and level of EI (High EI, Low EI) on learning achievement. There was no significant main effect of design type on learning achievement, $F(2,27)=$ $1.863, p=.175$ and also EI on learning achievement $F(1$, $27)=.116, \quad p=.736$. There was also no significant interaction effect between design type and EI on learning achievement $F(2,27)=1.305, p=.288$.

\section{B. Perceived Intrinsic Motivation}

A two-way ANOVA was done on design type (PosD, $\mathrm{NeuD}$, and NegD) and level of emotional intelligence (High EI, Low EI) on perceived intrinsic motivation. There was no significant main effect of design type on perceived intrinsic motivation, $F(2,27)=.893, p=.421$ and also EI on perceived intrinsic motivation $F(1,27)$ $=.193, p=.664$. There was also no significant interaction effect between design type and emotional intelligence on perceived satisfaction $F(2,27)=0.343, p=.713$.

\section{A. Learning Achievement}

Table 2. Learning Outcome Based on Design Type

\begin{tabular}{|c|c|c|c|}
\hline Learning system & Achievement & $\begin{array}{c}\text { Intrinsic Motivation } \\
\text { Mean, s.d. }\end{array}$ & $\begin{array}{c}\text { Satisfaction } \\
\text { Mean, s.d. }\end{array}$ \\
\hline Positive Design (PosD) & 2.18 & $5.396, .375$ & $6.124, .427$ \\
\hline Neutral Design (NeuD) & 2.09 & $5.316, .328$ & $5.684, .840$ \\
\hline Negative Design (NegD) & 4.00 & $5.516, .366$ & $6.182, .515$ \\
\hline
\end{tabular}

Table 3. Learning Outcome based on level of EI

\begin{tabular}{|c|c|c|c|}
\hline \multirow{2}{*}{ EI Category } & \multicolumn{3}{|c|}{ Learning Outcome (Mean, s.d) } \\
\cline { 2 - 4 } & Achievement & Intrinsic Motivation & Satisfaction \\
\hline High & 2.60 & $5.379, .377$ & $5.828, .802$ \\
\hline Low & 2.89 & $5.436, .346$ & $6.137, .445$ \\
\hline
\end{tabular}

Note: s.d = Standard Division

\section{Perceived Satisfaction}

A two-way ANOVA was done on design type (PosD, $\mathrm{NeuD}, \mathrm{NegD}$ ) and level of emotional intelligence (High EI, Low EI) on perceived satisfaction. There was a significant main effect between design type on perceived satisfaction, $F(2,27)=3.522, p=.044$. The highest perceived satisfaction was found for the NegD design $($ mean $=6.182)$ followed by PosD design $($ mean $=6.124)$ and NeuD design (mean $=5.684$ ). However the main effect of EI on perceived satisfaction was not significant, $F(1,27)=2.724, p=.110$. There is a significant interaction effect between design type and EI on perceived satisfaction $F(2,27)=5.168, p=.013$. Based on figure 3 , it can be concluded that even if the main effect of design type on perceived satisfaction was significant, it was qualified by an interaction between design type and level of EI.

For the PosD design, Low EI students had higher perceived satisfaction (mean=6.211, s.d.=.439) than High EI (mean=6.021, s.d.=.437). This is also true for the NeuD design as Low EI students portrayed higher perceived satisfaction (mean=6.184, s.d. =.358) than High EI (mean=5.084, s.d. =.884). However for the NegD design HIGH EI students portrayed higher perceived satisfaction (mean=6.379, s.d. $=.402$ ) than Low EI $($ mean=6.018, s.d. $=.570)$

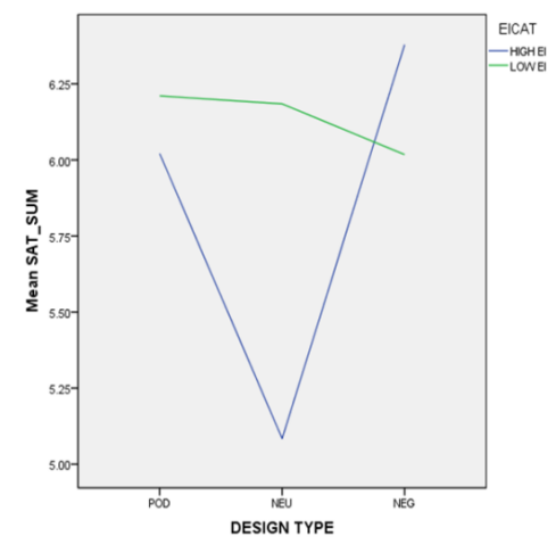

Fig.3. Line graph to depict the interaction effect between EI on design type towards perceived satisfaction. 


\section{DISCUSSION}

Based on the findings, it is found that there are higher number of students with low EI compared to high EI. However based on the mean value (mean $=4.730)$, it can be concluded that it is average. This is similar with the findings from [54] on polytechnic engineering students. It was also reported that there were no significant difference between students learning outcome when exposed to a Multimedia Learning Environment (MLE) that was design to either induce positive, neutral or negative emotions. Thus, hypothesis $\mathrm{H}_{1}$ is accepted. However, it was found that among all designs, students perform better in the NegD design compared to the other two designs (PosD and NeuD). Studies on the emotional effect on e-learning have always focused at comparing positive affect towards controlled or neutral design and being such side lined the influence of negative affect on learning [4], [21]. However a handful of study [27], [55], [56] portrayed a different picture. This study had similar outcome with [27] where induced positive emotion and specific negative emotion could improve the learning outcome and learning could be improved when there is an integration of an emotional strategy such as joy, fear or anger compared to a neutral design.

Then again, studies comparing the difference between positive, neutral and negative design have always claimed that students performed better when induced with positive emotion compared to other emotional strategies [3], [12], [28], [55]. Nevertheless, in this study it was found that students that were exposed to the NegD design performed better than the other design in all learning outcomes. This may also be due to the sample itself whom are polytechnic engineering students. Engineering students are known to be mildly introvert and introverts are known to prefer dark colours such as brown, grey and black [57],[58]. These students are also much more inclined towards the concept of outer space thus preferring cool colour such as dark colours that are reflected by the blue-grey combination [58].

Next, Hypothesis $\mathrm{HO}_{2}$ was also accepted as there was no significant difference between levels of EI on students learning achievement scores, perceived intrinsic motivation and perceived satisfaction when exposed to a Multimedia Learning Environment (MLE). Even though literature has revealed that students with High EI usually perform better than students with Low EI in an e-learning environment due to more self-discipline, being highly motivated, and achievement - oriented [31], [40], in this study the results has been opposite. A study done to determine the effect of computer based instructions towards EI found that students with low levels of EI have shown preference for non-linear, computer-based instruction which is a structured method of learning and students with high levels of EI were able to cope with either linear or non-linear type of computer instructions [31]. In this study, the MLE was designed as a non-linear, computer based instruction; hence a significant difference could not be determined as both categories of students have shown preference for this type of instruction.
On the other hand, individuals with low levels of EI might feel better in the cyber space claiming that they have higher levels of cyber emotional intelligence [59]. This scenario could also work vice-versa when the levels of EI are high. They added that an introverted person could be more motivated and successful in cyberspace as an influence from high levels of cyber EI. However it must be highlighted that introversion and extroversion characteristics in a person does not determine the levels of EI. both these personalities have their own socialemotional strengths that could contribute the high levels of emotional intelligence [60].

Next, Hypothesis $\mathrm{HO}_{3}$ and $\mathrm{HO}_{4}$ were also accepted as there was no significant difference between students level of EI on learning achievement scores and perceived intrinsic motivation when expose to a MLE. This is opposed to literature by [31], [40] that claims that students with high EI performs better that students with low EI in an e-learning environment. Even though, EI is related to intrinsic motivation [31], the relationship could not be establish in this context of a MLE . It was found that there was no significant interaction effect between students EI on learning achievement scores and perceived intrinsic motivation when expose to the MLE that was designed to induce positive, neutral or negative emotions. Hence, hypothesis $\mathrm{H}_{6}$ and $\mathrm{H}_{7}$ is accepted.

However, in the case of perceived satisfaction, it was found that design type and not levels of EI contributed towards this learning outcome. Hence, hypothesis $\mathrm{H}_{5}$ is accepted. It was reported that students were more satisfied with the NegD design followed by the PosD and NeuD design. It was also found that there is a significant interaction effect between students emotional intelligence on perceived satisfaction when expose to the MLE that was designed to induce positive, neutral or negative emotions that leads to rejecting hypothesis $\mathrm{HO}_{8}$. Even though EI was found to not contribute towards perceived satisfaction directly, it seems to moderate the relationship between design and perceived satisfaction. Students with low EI were much more satisfied with the PosD and NeuD design compared to High EI students that preferred the NegD design. Never the less, High EI students very much preferred design with emotionality (colour and character) compared to plain design such as the NeuD design. Students with Low EI were much more satisfied with PosD design and their satisfaction seem to plunge as it shifted to the NeuD and NegD design.

\section{CONCLUSION}

The objective of this study is to investigate how EI contributes towards learning outcome (learning achievement, perceived intrinsic motivation and satisfaction) in a MLE. In the context of design, overall students perform and perceived the NegD design as the most favourable and they were more motivated by the design. This could be due to the personality of the engineering students itself that prefer more "cyber" or cool colours. There was also no significant difference in learning outcome when students with high and low 
emotional intelligence were compared. However, students with low EI performed and perceived the MLE better than the students with High EI. This was expected as literature on cyber emotional intelligence claims that Low EI users would prefer online based interaction compared to the common social interaction when dealing with emotions.

Overall, EI was only qualified by perceived satisfaction in the context of designing to induce positive, neutral and negative emotion. It was found that Low EI students were more attracted towards vibrant colours and characters that induce positive emotion and high EI students preferred design with emotional strategies like colour, attractive font and images. Perhaps one of the major limitation of this study is that participants were only engineering students, maybe by broadening the study to cover more broader subject and disciplines might portray a different picture. In addition, as the number of students were limited to 33 participants as it is a preliminary, increasing the number of participant might result in a much more significant assessment. The study also did not assess the effect of gender and other characteristic that effect a person's emotional intelligence. It could all be suggested for future research in this area and the effect of emotional intelligence in the context of cyber emotional intelligence as it might have a bearing in e-learning.

\section{REFERENCES}

[1] E. Um, J. L. Plass, E. O. Hayward, and B. D. Homer, "Emotional design in multimedia learning.," Journal of Educational Psychology, vol. 104, no. 2, pp. 485-498, 2011.

[2] C. N. Moridis and A. A. Economides, "Toward computeraided affective learning systems: a literature review," Journal of Educational Computing Research, vol. 39, no. 4, pp. 313-337, Jan. 2008.

[3] C. Dong, "Positive emotions and learning: What makes a difference in multimedia design ?," New York University, 2007.

[4] N. Tractinsky, "Visual aesthetics," in The Encyclopedia of Human-Computer Interaction, M. Soegaard and R. F. Dam, Eds. Aarhus, Denmark: The Interaction Design Foundation, 2013.

[5] R. E. Mayer and G. Estrella, "Benefits of emotional design in multimedia instruction," Learning and Instruction, vol. 33, pp. 12-18, Oct. 2014.

[6] L. Arockiam and J. C. Selvaraj, "A study on relationship between emotional quotient and recollection \& retention in e-learning," International Journal on Computer Science and Engineering (IJCSE), vol. 3, no. 12, pp. 3748-3755, 2011.

[7] D. Leutner, "Motivation and emotion as mediators in multimedia learning," Learning and Instruction, vol. 29, pp. 174-175, Feb. 2014.

[8] A. H. A. Al-Faouri, "Investigating the impact of emotional intelligence on technology learning," International Journal of Engineering \& Technology, vol. 11 , no. 3, pp. 58-78, 2011.

[9] I. Lee, "Emotion, emotional intelligence, and e-learning," in ICoME2011(9th International Conference for Media in Education 2011), 2011.
[10] R. Pekrun, T. Götz, W. Titz, and R. P. Perry, "Positive emotions in education," in Beyond Coping: Meeting Goals, Visions, and Challenges, E. Frydenberg, Ed. Oxford University Press New York, 2002, pp. 149-173.

[11] R. Pekrun, "Emotions as drivers of learning and cognitive development," New Perspectives on Affect and Learning Technologies. Explorations in the Learning Sciences, Instructional Systems and Performance Technologies, vol 3, no. 1, pp. 23-39, 2011.

[12] E. R. Um, "The effect of positive emotions on cognitive : Processes in multimedia-based learning," New York University, 2008.

[13] D. A. Norman, Emotional Design: Why We Love (or Hate) Everyday Things. New York: Basic Books, 2004.

[14] C. Hinton, K. Miyamoto, and B. Della-Chiesa, "Brain research, learning and emotions: implications for education research, policy and practice," European Journal of Education, vol. 43, no. 1, pp. 87-103, Jan. 2008.

[15] R. E. Mayer, "Applying the science of learning to medical education.," Medical education, vol. 44, no. 6, pp. 543-9, Jun. 2010.

[16] R. E. Mayer, Multimedia Learning, 2nd ed. New York: Cambridge University Press, 2009.

[17] K. Knautz, "Emotion felt and depicted : consequences for multimedia retrieval," in Indexing and Retrieval of NonText Information, D. R. Neal, Ed. Berlin, Boston, MA: De Gruyter Saur, 2012, pp. 343-375.

[18] H. Van Der Meij, "Designing for user cognition and affect in software instructions," Learning and Instruction, vol. 18, no. 1, pp. 18-29, Feb. 2008.

[19] M. Martinez, "Beyond classroom solutions : New design perspectives for online learning," Educational Technology \& Society, vol. 5, no. 2, pp. 1-6, 2002.

[20] E. R. Um, H. S. Song, and J. L. Plass, "The effect of positive emotions on multimedia learning," in Proceedings of World Conference on Educational Multimedia, Hypermedia and Telecommunications 2007, 2007, no. 1981, pp. 4176-4185.

[21] C. Dong, "Interface design, positive emotions and multimedia learning," in Handbook of Research on Human Performance and Instructional Technology, $\mathrm{H}$. Song and T. T. Kidd, Eds. Hershey, PA: Information Science Reference, 2010, pp. 182-194.

[22] J. B. Nezlek, K. Vansteelandt, I. Van Mechelen, and P. Kuppens, "Appraisal-emotion relationships in daily life.," Emotion, vol. 8, no. 1, pp. 145-50, Feb. 2008.

[23] S. P. Anderson, Seductive Interaction Design : Creating Playful, Fun, and Effective User Experiences, vol. 67. Berkeley, CA: New Riders, 2011.

[24] P. Hekkert, "Design aesthetics : principles of pleasure in design," Psychology Science, vol. 48, no. 2, pp. 157-172, 2006.

[25] A. G. Ho and K. W. M. Siu, "Emotionalise design, emotional design, emotion design : a new perspective to understand their relationships," in International Association of Societies of Design Research, 2009, pp. 2717-2726.

[26] C. Miller, G. Veletsianos, and S. Hooper, "Demystifying aesthetics: An exploration of emotional design," in Proceedings of the Ninth IASTED International Conference Computers and Advanced Technology in Education, 2006, pp. 15-20.

[27] R. Ghali and C. Frasson, "Emotional strategies for vocabulary learning," in 2010 10th IEEE International Conference on Advanced Learning Techologies, 2010. 
[28] R. Khairudin, M. V. Givi, W. S. Wan Shahrazad, R. Nasir, and F. W. Halim, "Effects of emotional contents on explicit memory process," Pertanika Journal of Social Sciences \& Humanities (JSSH)., vol. 19, pp. 17-26, 2011.

[29] S. Naidu, E-learning: A Guidebook of Principles, Procedures and Practices. New Delhi: Commonwealth Educational Media Centre for Asia (CEMCA), 2006, pp. $1-88$.

[30] R. G. Saadé and D. Kira, "The emotional in e-learning," Journal of Asynchronous Learning Networks, vol. 13, no. 4, pp. 57-73, 2009.

[31] C. Behnke and J. P. Greenan, "The relationship between emotional intelligence and attitudes toward computerbased instruction of postsecondary hospitality students," Journal of Career and Technical Education, vol. 26, no. 1, pp. 62-84, 2011.

[32] A. G. Barto and O. Simsek, "Intrinsic motivation for reinforcement learning systems," In Thirteenth Yale Workshop on Adaptive and Learning Systems, pp. 113$118,2005$.

[33] M. Chang and J. D. Lehman, "Interactive multimedia program: An experimental study on the effects of the relevance component," CALICO Journal, vol. 20, no. 1, pp. 81-98, 2002.

[34] J. S. Jung and K. Y. Lim, "Effect analysis of factors related to the learner participation, achievement, and satisfaction in the web-based online discussion.," Journal of Educational Technology, vol. 16, no. 2, pp. 107-135, 2009.

[35] S. Liaw, "Investigating students' perceived satisfaction, behavioral intention, and effectiveness of e-learning: A case study of the blackboard system," Computers \& Education, vol. 51, no. 2, pp. 864-873, Sep. 2008.

[36] I. Lee, H. Park, E. Ryu, N. Oh, and S. Jan, "Analysis on relationship among learning affection, emotional intelligence, learning satisfaction, and learning flow of university student," in ICoME2012 (10th International Conference for Media in Education 2012), 2012, p. p.90.

[37] P. Salovey and J. D. Mayer, "Emotional intelligence," in Imagination, Cognition, and Personality, vol. 9, Bantam, 1990, pp. 185-211.

[38] C. Lawson, "The connections between emotions and learning," Centre of Development and Learning, 2002. [Online]. Available: http://www.cdl.org/resourcelibrary/articles/connect_emotions.php. [Accessed: 01Apr-2012].

[39] H. Aminuddin, S. Tajularipin, and I. Rohaizan, "Philosophy underlying emotional intelligence in relation to level of curiosity and academic achievement of rural area students.," Journal of Social Sciences, vol. 5, no. 2, pp. 95-103, 2009.

[40] R. Berenson, G. Boyles, and A. Weaver, "Emotional intelligence as a predictor for success in online learning," The International Review of Research in Open and Distance learning, vol. 9, no. 2, 2008.

[41] B. A. Frey and J. M. Sutton, "A model for developing multimedia learning projects," MERLOT Journal of Online Learning and Teaching, vol. 6, no. 2, pp. 491-507, 2010.

[42] H. Zettl, Sight, Sound, Motion: Applied Media Aesthetics. BELMONT: Wadsworth Pub Co, 2010.

[43] A. D. Shaikh, B. S. Chaparro, and D. Fox, "Perception of fonts: Perceived personality traits and uses," Usability News, 2006. [Online]. Available: http://usabilitynews.org/perception-of-fonts-perceivedpersonality-traits-and-uses/. [Accessed: 03-Jun-2013].
[44] A. D. Shaikh, "Psychology of onscreen type: Investigations regarding typeface personality, appropriateness, and impact on document perception," Wichita State University, 2007.

[45] D. Tsonos and G. Kouroupetroglou, "A methodology for the extraction of reader' $\mathrm{s}$ emotional state triggered from text typography," www.intechopen.com, 2007. [Online]. Available: www.intechopen.com/download/pdf/5301. [Accessed: 17-Feb-2012].

[46] W. Wang and Y. Yu, "Image emotional semantic query based on color semantic description," in Proceedings of the Fourth International Conference on Machine Learning and Cybernetics, 2005, no. August, pp. 45714576.

[47] I. Ipek, "The effect of CBI lesson sequence type and field dependence on learning from computer-based cooperative instruction in web," The Turkish Online Journal of Educational Technology -, vol. 9, no. 1, pp. 221-234, 2010.

[48] M. A. Manal, "Achievement goals and intrinsic motivation: A case of IIUM," International Journal of Humanities and Social Science, vol. 1, no. 6, pp. 196-206, 2011.

[49] Y. Wang, "Assessment of learner satisfaction with asynchronous electronic learning systems," Information \& Management, vol. 41, no. 1, pp. 75-86, Oct. 2003.

[50] P. Ramakrisnan, J. Azizah, and M. Y. Noor Faezah, "Towards an understanding of user satisfaction measurement in online discussion site (ODS) design using rasch analysis," International Journal of Education and Research, vol. 1, no. 6, pp. 1-12, 2013.

[51] K. V. Petrides and A. Furnham, "The role of trait emotional intelligence in a gender-specific model of organizational variables.," Journal of Applied Social Psychology, vol. 35, pp. 552-569, 2006.

[52] T. S. Lim, "Gender differences in emotional intelligence: are you as smart as you think emotionally?," Universiti Tunku Abdul Rahman, 2011.

[53] A. R. Roslina, Fifi Afiyah, and A. R. Wan Rafaei, "A cross cultural study of achievement motivation and its relationship with emotional intelligent between Indonesian and Malay female students of IIUM," in The 6th International Postgraduate Research Colloqium, 2009 no. 1990, pp. 83-97.

[54] J. A. Kumar and B. Muniandy, "The influence of demographic profiles on emotional intelligence: A study on polytechnic lecturers in Malaysia," International Online Journal of Educational Sciences, vol. 4, no. 1, pp. 62-70, 2012.

[55] S. Chaffar and C. Frasson, "The emotional conditions of learning," in The 18th International Florida Artificial Intelligence Research Society (FLAIRS) Conference, 2005, pp. 201-206.

[56] S. Lewis, M. Dontcheva, and E. Gerber, "Affective computational priming and creativity," in Proceedings of the 2011 Annual Conference on Human Factors in Computing Systems - CHI '11, 2011.

[57] P. Kirkham, D. Farkas, and M. Lidstrom, "Learning styles data and designing multimedia for engineers," 2006 IEEE International Professional Communication Conference, no. 1, pp. 57-67, Oct. 2006

[58] D. Cigić and V. Bugarski, "Personality traits and colour preferences," Current Topics in Neurology, Psychiatry and Related Disciplines; Journal of Association of Serbian Neurologists, vol. 18, no. 4, 2010.

[59] A. Youssef and H. Youssef, "Social networking on Web 2.0: From emotional intelligence to cyber emotional 
intelligence," Management Information Systems, vol. 6, no. 2, pp. 0-7, 2011.

[60] M. Zeidner, G. Matthews, and R. D. Roberts, What We Know about Emotional Intelligence: How it Affects Learning, Work, Relationship and our Mental Health. Cambridge, Massachusetts: The MIT Press, 2009.

\section{Authors' Profiles}

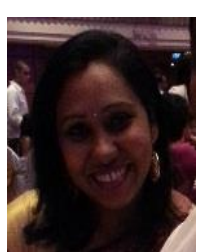

Jeya Amantha Kumar is currently a $\mathrm{PhD}$ candidate in the Centre for Instructional Technology and Multimedia, Universiti Sains Malaysia, Pulau Pinang, Malaysia. Her research interest is in the field of emotional design, emotional intelligence, emotions in elearning and aesthetics in user interface. She has experience working in the Malaysian polytechnic system as a lecturer in electrical engineering for the past 11 years.

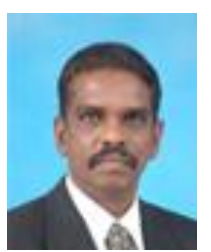

Prof. Dr. Balakrishnan Muniandy is a lecturer in the Centre for Instructional Technology and Multimedia, Universiti Sains Malaysia, Pulau Pinang, Malaysia. In teaching, he has been focusing on multimedia authoring, management and evaluation of multimedia project, instructional design and delivery and research methods and issues in instructional multimedia.
Dr.Balakrishnan received his $\mathrm{PhD}$ in Educational Leadership (Educational Technology) from the Department of Leadership, Technology \& Administration (DELTA), University of Oregon, United States of America.

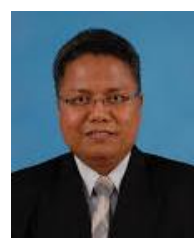

Assoc. Prof. Dr. Wan Ahmad Jaafar Wan Yahaya is the Director for the Centre of Alumni Liaison for Universiti Sains Malaysia. Dr. Wan has served as the Deputy Dean for the Centre for Instructional Technology and Multimedia, Universiti Sains Malaysia. In teaching, he has been focusing on Graphic 2D, 3D \& Animation, Multimedia Project Management, Multimedia in Education, and 3D Visualisations and Animations. Dr. Wan Ahmad Jaafar received his $\mathrm{PhD}$ in Multimedia in Education from the University of Leeds, United Kingdom.

How to cite this paper: Jeya Amantha Kumar, Balakrishnan Muniandy, Wan Ahmad Jaafar Wan Yahaya,"Emotional Design in Multimedia Learning: How Emotional Intelligence Moderates Learning Outcomes", International Journal of Modern Education and Computer Science(IJMECS), Vol.8, No.5, pp.54-63, 2016.DOI: 10.5815/ijmecs.2016.05.07 